\title{
FUNÇÃO DISCURSIVA DOS ELOS COESIVOS REFERENCIAIS
}

\author{
Mônica Magalhães Cavalcante*
}

\begin{abstract}
Resumo: Sugerimos, aqui, a reorganização dos elos coesivos classificados por Koch (1989), orientados pela retomada, em manutenções referenciais; ou pela mera remissão a certas âncoras cotextuais ou a proposições encapsuladas em introduções referenciais. Além disso, consideraremos alguns critérios lexicais para distinguir elementos recategorizadores.
\end{abstract}

Palavras-chave: Coesão. Referência. Anáfora. Dêixis.

\begin{abstract}
We suggest, here, a reorganization of cohesive links proposed by Koch (1989), guiding by retaking, in reference maintenances; or by the mere remission to certain anchors in co-text, or to encapsulated propositions, in reference introductions. Besides, we will consider some lexical criteria for distinction between recategorizated elements.
\end{abstract}

Keywords: Cohesion. Reference. Anaphora. Deixis.

\section{Introdução}

O limite entre o estudo da coesão e a análise de processos referenciais é muito mais extenso do que normalmente se costuma supor. É antes uma escolha de perspectiva do que uma focalização de paisagens distintas.

Este trabalho superpõe as páginas de dois conteúdos amplamente abordados na Lingüística de Texto, mas geralmente divorciados nas pesquisas sobre o assunto: elos coesivos e elementos referenciais. Falar de elos coesivos tem sido descrever como se obtém a unidade formal de um texto; tratar de elementos referenciais tem sido demonstrar como funcionam, no discurso, diferentes estratégias de remissão e/ou de retomada.

Se neste artigo nada revelaremos de novo sobre esse assunto, pelo menos the vestiremos outro traje, ou desnudaremos roupagem antiga para examinar-lhe melhor o feitio.

\section{Coesão e coerência: aproximações e distanciamentos}

O conceito de coesão nem sempre aparece inteiramente claro na literatura. Halliday e Hasan (1976) se baseiam num critério semântico-discursivo quando afirmam que a coesão se verifica sempre que, para se interpretar um elemento no discurso, se recorre à interpretação de um outro. A coesão estabelece, portanto, relações de sentido, e é por essa razão que, para os autores, representa uma condição necessária para a configuração da textualidade.

Cremos que é justamente por ser definida por Halliday e Hasan como uma complexa rede de relações de coerência que a coesão se confunde, a nosso ver, com a própria noção de coerência. Assim sendo, a investigação da coesão passa a ser supervalorizada pelos autores, que chegam ao ponto de afirmar que, por este fator de textualidade, é possível diferenciar um texto de um não-texto ${ }^{1}$.

Em vista dessas considerações, não adotaremos tal abordagem da coesão, pelo grau de imprecisão que parece envolvê-la. Pressupomos, aqui, a seguinte definição de Koch (2002; ver também Marcuschi, 1983), com fundamento em Beaugrande e Dressler (1981):

\footnotetext{
* Doutora em Linguística. Professora Associado I de Linguística da Universidade Federal do Ceará.

${ }^{1}$ Isso é reiterado por Fonseca (1992, p.11): "Numa formulação genérica, Halliday e Hasan reúnem sob a designação de coesão todos os nexos semânticos que se estabelecem entre os Ens [enunciados] por que se realiza o texto."
} 
"o conceito de coesão textual, portanto (...), diz respeito a todos os processos de seqüenciação que asseguram (ou tornam recuperável) uma ligação lingüística significativa entre os elementos que ocorrem na superfície textual" (VILELA, KOCH, 2001, p. 467). A coesão seria, por esse prisma, uma espécie de expressão lingüística, por meio de elos coesivos, explícitos ou subentendidos, das relações de coerência.

Podemos dizer, que, quando dão a entender que não existe texto sem coesão, Halliday e Hasan se mantêm fiéis, na verdade, às propriedades essencialmente semânticas que julgam atribuir ao fenômeno. Do mesmo modo, Beaugrande e Dressler (e seguidores) são fiéis a seus pressupostos teóricos quando defendem que é perfeitamente possível haver textos destituídos de coesão (como manifestação lingüística das relações de sentido), e que ela não é condição nem necessária nem suficiente para a construção da coerência.

Fonseca (1992, p. 16-17) evidencia alguns pontos fundamentais da proposta de Halliday e Hasan (1976) e pondera que, de acordo com estes autores, a coesão:

a) concerne aos traços que caracterizam o texto quanto ao modo como ele está construído como edifício semântico;

b) constitui complemento indispensável à articulação explícita dos sentidos essenciais do texto; cumpre uma espécie de função de catálise em relação aos outros componentes do sistema;

c) é realizada por recursos lingüísticos, manifestados explicitamente na imanência do texto; tais recursos assumem um caráter eminentemente relacionador, assegurando a continuidade semântica entre os enunciados.

Importa observar, no entanto, que, apesar de definirem coesão segundo um princípio de dependência semântica, Halliday e Hasan terminam descrevendo o fenômeno, de maneira bastante detalhada, como um conjunto de recursos lingüísticos que se realizam no texto criando-lhe tessitura e possibilitando ao ouvinte/leitor diferenciá-lo de uma mera sequiência de enunciados. Reconhecer a tessitura de um texto é, para os autores, cumprir uma das funções que comporiam o sistema lingüístico: a função textual. De par com ela, e vinculando-se a ela estreitamente, operariam duas outras funções da linguagem: a ideacional e a interpessoal.

Como sintetiza Fonseca (1992, p. 9-10), a coesão, para Halliday e Hasan, se enquadraria no seguinte esquema de textura (ou tessitura):

a) textura externa: que tem a ver com a consistência de 'registro'; envolve fatores externos que afetam as escolhas lingüísticas, como a natureza da audiência, o meio, os propósitos comunicativos etc.

b) textura interna:

- ao nível supra-enunciados: que englobaria aspectos superestruturais e macroestruturais, estabelecendo um texto como um gênero particular;

- ao nível intra-enunciados: que se relaciona, de um lado, à organização de tema e rema e, de outro, à articulação de informação dada e nova;

- ao nível inter-enunciados: que respeita aos nexos semânticos expressos por laços coesivos.

Uma observação atenta desse quadro nos leva à constatação de que as noções de textualidade para Halliday e Hasan (1976) e Beaugrande e Dressler (1981) muito mais se aproximam do que se separam. Assim é que, dos sete fatores de textualidade apontados por Beaugrande e Dressler, dois estariam ligados à substância lingüístico-conceitual de um texto: a coesão e a coerência; e os outros cinco se relacionariam a aspectos pragmáticos: a intencionalidade, a aceitabilidade, a situacionalidade, a informatividade e a intertextualidade. 
Diríamos, então, que os fatores de natureza lingüística e conceitual estariam, grosso modo, para a textura interna, assim como alguns fatores de ordem pragmática estariam para a textura externa; outros, porém, parecem estabelecer-se nos dois parâmetros ao mesmo tempo. A coesão, como manifestação lingüística da coerência, corresponderia ao nível interenunciados. A coerência se aproximaria do nível supra-enunciados, embora, na classificação de Halliday e Hasan, este nível contemple, além da lógica interna do texto, características formais e macroproposicionais de um dado gênero. A intencionalidade, a aceitabilidade e a situacionalidade seriam proporcionais aos aspectos da textura externa, àquelas condições extralingüísticas que determinam decisões semântico-estruturais. A intencionalidade diz respeito aos propósitos enunciativos do falante, ou à força ilocucionária que ele pretende dar a seus enunciados e ao esforço que faz para ser compreendido pelo recebedor. A aceitabilidade concerne à mobilização do destinatário para se tornar cooperativo (cf. Grice, 1975) e alcançar o conteúdo e a pertinência da mensagem. E a situacionalidade, que seria melhor designada como "contextualidade", abrange um conjunto de circunstâncias contextuais, como grau de familiaridade entre os interlocutores, a formalidade da situação comunicativa, os conhecimentos de mundo dos participantes, dentre outros.

Por fim, a informatividade e a intertextualidade congregam traços de textura externa e interna, simultaneamente, a nosso ver. Um texto é mais informativo na medida em que acrescenta informações não-esperadas, conhecidas ou não. Eis por que relacionamos esse fator de textualidade ao nível intra-enunciados da textura interna, no que tange, especificamente, à organização dos conteúdos velhos e novos no texto ${ }^{2}$. Todavia, uma vez que a previsibilidade está diretamente relacionada ao conhecimento compartilhado, julgamos que a informatividade se prenda também a fatores de textura externa. Dessa forma, como acrescenta Costa Val (1991, p. 14), um bom índice de informatividade supõe "suficiência de dados".

Isso significa que o texto tem que apresentar todas as informações necessárias para que seja compreendido com o sentido que o produtor pretende. Não é possível nem desejável que o discurso explicite todas as informações necessárias ao seu processamento, mas é preciso que ele deixe inequívocos todos os dados necessários à sua compreensão aos quais o recebedor não conseguirá chegar sozinho.

Quanto à intertextualidade, ela não equivale precisamente a nenhum item da proposta de Halliday e Hasan, conquanto partilhe tanto de características da textura interna, também no que atende à distribuição de dado e novo, quanto de características da textura externa, no que concerne à memória comum dos interlocutores. A intertextualidade toca ao fato de todo texto se construir a partir de formas ou de conteúdos de outros textos. Assim sendo, se ela se constrói a partir de propriedades semânticas e estruturais, por outro lado tais aspectos lingüísticos dependem de um traço extralingüístico fundamental para cumprir sua finalidade: o (re)conhecimento dos participantes da comunicação.

Ambos os modos de distribuição dos fatores de textualidade, tanto de Halliday e Hasan quanto de Beaugrande e Dressler, fazem uma organização meramente didática desses parâmetros, que na verdade se imbricam, se interdependem e convergem - orquestrados pelo princípio de cooperação que motiva os interlocutores - para a construção de um valor mais alto: a coerência. Não a coerência entendida como simples mecanismo de conectividade de

\footnotetext{
${ }^{2}$ Costa Val (1991, p. 14) argumenta que, por outro lado, se "o texto se mostrar inteiramente inusitado, tenderá a ser rejeitado pelo recebedor, que não conseguirá processá-lo”. É importante, portanto, que haja equilíbrio na dosagem de informações dadas e novas.
} 
relações semânticas explicitamente postas no cotexto, ou a ele subjacentes, mas a coerência que se nutre de condições contextuais múltiplas.

Se nos ativermos a essa noção mais ampla de coerência, poderemos, na mesma esteira, propor um outro olhar para a coesão que não se circunscreva a aspectos formais da articulação de enunciados, o que, nas palavras de Fonseca (1992, p. 26), apenas garante "a boa formação semântico-sintática do transfrástico".

É também de Fonseca (1992, p. 28-9) a conclusão que retemos como pressuposto para este trabalho:

Na noção de coesão a adoptar neste estudo, tentarei integrar as dimensões centrais focadas por Halliday-Hasan com outras fortemente operantes na configuração da unidade e da continuidade semânticas do texto, cuja caracterização requer, iniludivelmente a consideração das coordenadas da enunciação, logo, uma óptica pragmático-comunicativa, que necessariamente se desligará da estrita sintagmática imanente desta unidade lingüística - ou melhor, a penetrará à luz daquelas dimensões.

Para a configuração clara da noção de coesão anunciada, interessará caracterizar antes o que, particularmente no âmbito da chamada Lingüística de Texto, vem sendo apresentado como a grande dimensão definidora do texto, a saber a sua coerência.

\section{Para além da coesão}

A descrição formal de elos coesivos que a seguir apresentamos é proposta por Koch (1989) e revista pela autora em Vilela e Koch (2001), com algumas alterações. Sob influência da perspectiva transfrástica que ainda norteava a Lingüística Textual no Brasil, a autora propõe seu modelo como um remapeamento da seguinte classificação de Halliday e Hasan (1976):

- referência, quando um elemento do texto remete a outro, necessário a sua interpretação; pode ser pessoal, demonstrativa ou comparativa;

- substituição, quando um elemento do texto é colocado no lugar de outro, para evitar repetição; pode ser nominal, verbal ou frasal;

- elipse, quando um elemento do texto é substituído por zero e, assim, como a classificação anterior, pode ser nominal, verbal ou frasal;

- conjunção, quando se estabelecem relações semânticas entre elementos ou orações do texto; pode ser aditiva, adversativa, causal, temporal ou continuativa;

- coesão lexical, quando um elemento lexical substitui um outro elemento lexical do texto, numa relação ou de "repetição" ou de contigüidade semântica; por isso pode ser por reiteração ou por colocação.

Argumentando contra a fragilidade da classificação de Halliday e Hasan, e fazendo coro com outros autores (dentre eles, Brown e Yule, 1983) que igualmente criticavam a sobreposição dos critérios que definem os processos de "referência, substituição, elipse e coesão lexical", Koch pleiteia que essas quatro classes de elos coesivos fiquem agasalhadas num rótulo único de "coesão referencial"3. A ela se oporia um equivalente da conjunção

\footnotetext{
${ }^{3}$ Define a autora: "Denomina-se coesão referencial aquela em que um componente da superfície do texto faz remissão a outro(s) elemento(s) do universo textual. O primeiro constitui a forma referencial ou remissiva e o segundo é o elemento de referência ou referente textual" (VILELA; KOCH, 2001, p. 474).
} 
hallidayana: a "coesão seqüencial", aquela que instala entre segmentos do texto relações semânticas e/ou pragmáticas. Neste artigo, vamos cingir-nos especificamente à coesão referencial.

Fixando-se principalmente em configurações formais das relações coesivas, Koch divide os laços referenciais em formas gramaticais (que podem ser presas ou livres) e formas lexicais, conforme se observa no esquema abaixo:

Formas remissivas ou referenciais

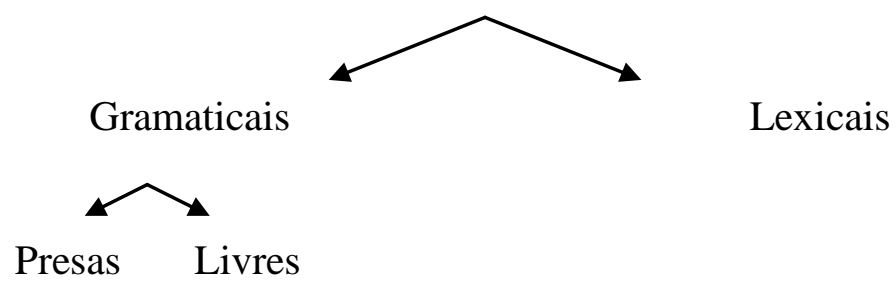

3.1 Formas referenciais gramaticais: não fornecem instruções de sentido; apenas instruções de conexão.

3.1.1 Formas referenciais gramaticais presas: são as que se prendem sintaticamente ao nome; exercem a função de determinantes dentro do grupo nominal. Expressam-se por:

- artigos definidos e indefinidos;

- pronomes adjetivos (demonstrativos, possessivos, indefinidos e interrogativos);

- numerais cardinais e ordinais.

Sem negar a importância desses elementos com função semelhante à do "artigo", julgamos que sua relevância reside muito mais em seu caráter remissivo, que pode apontar para diferentes campos dêiticos, do que em sua natureza essencialmente referencial. A função referencial é, com efeito, desempenhada não por eles em si mesmos, mas pelo sintagma nominal inteiro que as contém. Assim, quando empregamos, por exemplo, um pronome demonstrativo em substituição a um artigo definido, não se modifica simplesmente a forma, mas o tipo de remissão, que visa a atingir mais intensamente o destinatário. Outras vezes, o demonstrativo tem o intuito de enviar a atenção do receptor para espaços da memória comum dos participantes da enunciação, como se dá em (1), abaixo:

(1) "Deve-se instituir uma censura para a Internet? De que maneira evitar que essa rede planetária, sem dono, sem sede, sem responsável e sem controle, seja tão invasiva e perniciosa quando posta a serviço do terrorismo, dos atentados, da pedofilia, da prostituição infantil ou da difusão de fórmulas e receitas de morte?" (artigo de opinião - JoAO1 - Protexto).

Note-se o papel de saliência discursiva que exerce o demonstrativo ao chamar a atenção para atributos, como informações novas, que são acrescentados à designação anterior. Em outras situações, ainda, o demonstrativo, além de salientar a recategorização do referente, como em (1), também imprime à denominação um valor afetivo, como que aproximando dos interlocutores a entidade em foco. Veja-se isto no exemplo de Apothéloz e Reichler-Béguelin (1999):

(2) "On planes of recent construction, computers enable us to check the good working order of the instruments on board. This marvelous and 
sophisticated tool is assumed to eliminate to a maximum the possibility of human error."

Não demoraremos muito na consideração dessas formas gramaticais presas, justamente pela não autonomia referencial que as caracteriza. Passaremos, então, ao segundo tipo descrito pela autora.

3.1.2 Formas referenciais gramaticais livres: são as que substituem todo o grupo nominal; trata-se das chamadas "pró-formas", que se manifestam por:

- pronomes pessoais

- demonstrativos

- possessivos

- indefinidos

- interrogativos

- relativos

- numerais cardinais, ordinais, multiplicativos e fracionários

- advérbios pronominais

- expressões adverbiais

- formas verbais remissivas

Este grupo extenso de mecanismos formais variados ganha mais heterogeneidade quando o observamos sob o ângulo da referenciação que eles mediatizam. O primeiro ponto a salientar é que, embora pareçam meros substitutos de referentes anteriormente introduzidos no texto, e portanto correferenciais com eles, nem todos operam uma retomada total e pontual de objetos do discurso, como o fazem os pronomes pessoais, por exemplo. Assim, paralelamente a ele, ela correferenciais, como em (3), temos casos de retomada parcial, muito frequientes com indefinidos, interrogativos e numerais, como em (4):

(3) As crianças estão viajando. Elas só voltarão ao final do mês. (VILELA; KOCH, 2001, p. 481).

(4) Os amigos acorreram. Cada um trazia uma pequena contribuição. (VILELA; KOCH, 2001, p. 483).

Outro ponto interessante a notar é que demonstrativos e advérbios se sobressaem nesse rol de elos gramaticais, por não exercerem função apenas referencial, mas também dêitica: desempenham no discurso um procedimento dêitico (Ehlich, 1992) de monitoração da atenção dos interlocutores. Tais elementos por vezes marcam pontos específicos no texto, onde o antecedente deve ser identificado, como em (5); ou apontam para locais referidos sob a pressuposição do lugar de origem do falante, como em (6):

(5) Luís e Márcio trabalham juntos num escritório de advocacia. Este dedica-se a causa criminais, aquele a questões tributárias. (VILELA; KOCH, 2001, p. 482)

(6) Perto do parque há um pequeno restaurante. Lá se reúnem muitos jovens ao entardecer. (VILELA; KOCH, 2001, p. 482)

Esses traços de saliência discursiva e de pressuposição das coordenadas da enunciação emprestam aos demonstrativos e advérbios um comportamento genuinamente dêitico. Mas a deiticidade, como mostramos em pesquisa anterior (ver Cavalcante, 2000), varia em medida escalar. Compare-se, por exemplo, (7) e (8), em que, respectivamente, o advérbio é um sinalizador de posições na linearidade textual, sendo portanto altamente 
dêitico, ao passo que o demonstrativo é um encapsulador, de baixa deiticidade, que só se diferencia dos anafóricos correferenciais por não retomar referentes específicos, e resumir porções textuais difusas:

(7) Abaixo, apresentaremos os cinco exemplos da situação descrita acima.

(8) Antônio pensa que seu time vai ganhar o campeonato, mas eu não acredito nisso. (VILELA; KOCH, 2001, p. 482).

Opondo-se aos elementos que cumprem a função gramatical das pró-formas, encontram-se os elos referenciais lexicais, que descrevemos a seguir.

3.2 Lexiciais: grupos nominais definidos que fornecem instruções de conexão e instruções de sentido, porque, segundo a autora, fazem referência a algo no mundo extralingüístico.

Diríamos que a diferença entre as formas gramaticais e as lexicais se estabelece no âmbito do sentido e da denotação, não no âmbito da referência. Mesmo porque a concepção de referência hoje mantida na Lingüística de Texto renuncia à correspondência direta entre a designação e as entidades do mundo real, e se assenta numa representação dos objetos negociada e construída durante a enunciação.

Veremos, pelos exemplos abaixo discriminados, que a coesão firmada por elos lexicais costuma recategorizar referentes, somando significados e atributos e - principalmente - veiculando pontos de vista do enunciador, o que lhes dá enorme força argumentativa.

\section{- grupos nominais definidos}

(9) Nos últimos tempos, dezenas de parlamentares mudaram seu domicílio fiscal para Brasília. Até aí, beleza. Só que, no processo de transferência, $\underline{\mathbf{o}}$ Leão abriu os olhos, afiou as garras e levou trinta deles para a malha fina. (nota - Veja, 18/09/02)

\section{- nominalizações}

(10) A concentração de clorofluorcarbono (CFC) na atmosfera caiu bastante, como revela um estudo da ONU divulgado há duas semanas. Se a queda continuar nesse ritmo, o buraco na camada ozônio poderá estar totalmente fechado dentro de cinqüenta anos. (notícia - Veja, 09/10/02)

\section{- expressões sinônimas ou quase-sinônimas}

(11) A possibilidade de introduzir uma nova referência contida na expressão anafórica por meio de outra referência mencionada previamente implica que há algum tipo de relacionamento entre essas duas referências. E essa relação não é somente contextual, mas também 'genérica'. (tese - inédita)

\section{- hiperônimos ou indicadores de classe}

(12) Jakob von Metzler, de 11 anos, era filho de um rico banqueiro alemão de Frankfurt, mas voltava da escola sempre de ônibus. Passava das 11 da manhã de sexta-feira 27 quando ele desceu num ponto a uma quadra de casa. Duas horas depois, a família recebia um telefonema informando o sequiestro. $\mathrm{O}$ desfecho do caso, na terça-feira, chocou a Alemanha. O corpo da criança foi encontrado no fundo de um lago, a 60 quilômetros da cidade. Estava 
enrolado num saco plástico e tinha sinais de estrangulamento (notícia - Veja, 09/10/02).

\section{- nomes genéricos}

(13) Com a história do confisco, as pessoas tiveram de renunciar à compra da casa própria, a uma cirurgia, a uma viagem, a uma série de coisas (entrevista, Isto é, 18/09/02).

\section{- repetições com ou sem mudança de determinante}

(14) Os estudiosos que defendem uma concepção mais ampla entendem que anáfora associativa é toda anáfora não correferencial. Partidário dessa concepção, Berrendonner (1995), postula ser essa anáfora uma configuração discursiva que apresenta uma expressão referencial dotada de duas propriedades (tese - inédita).

\section{- SN rotuladores}

(15) Quem acompanha o discurso dos candidatos com atenção também percebe que as propostas para chegar próximo do eldorado do pleno emprego são muito parecidas. Retomar o crescimento econômico, priorizar a agricultura, incentivar as exportações, dar uma força para o turismo. $\underline{\mathrm{O}}$ diagnóstico está posto. Os atalhos também: reeducar a mão-de-obra, criar estágios para os jovens, liberar financiamentos para os pequenos empresários, apostar na agricultura familiar. (carta ao leitor, Isto é, 18/09/02).

\section{- SN definidos, possessivos ou demonstrativos}

(16) Cartuchos e toners falsificados comprometem a qualidade da impressão do seu trabalho. Para garantir que você está comprando cartuchos originais $\mathrm{hp}$, preste atenção no selo de garantia, no lado direito da embalagem. Ele deve mudar de verde para azul, de acordo com o ângulo de visão. Abra os olhos. Cartuchos originais hp têm selo de garantia que muda de cor. (anúncio comercial de HP).

(17) Collor,

Alagoas e o Brasil agradecem a veiculação da reportagem 'Mais uma de Collor dez anos depois' (2 de outubro), sobre o novo escândalo no aniversário de dez anos de sua queda (impeachment). Na hora exata! Parabéns. É dessa imprensa que necessitamos. (carta do leitor, Veja, 9/10/02)

Sob o critério da referenciação, primeiro, poderíamos separá-los em quatro grupos:

a) os que fazem retomada total, sendo correferenciais, que incluem os grupos nominais definidos, os sinônimos, os hiperônimos, os nomes genéricos e as repetições;

b) os que fazem retomada parcial, que podem incluir também nomes genéricos e repetições;

c) os que não fazem retomada e introduzem um referente novo no discurso; trata-se das anáforas indiretas, que se expressam principalmente por SN definidos, possessivos ou demonstrativos;

d) os que não fazem retomada e também introduzem um referente novo no discurso, mas resumindo conteúdos proposicionais; trata-se dos encapsuladores, que se manifestam por SN rotuladores, nominalizações ou nomes genéricos. 
Uma análise mais acurada distinguiria, ainda, dentre os grupos acima, as formas híbridas que contivessem algum grau de deiticidade e remetessem a mais de um espaço dêitico. Mas esta pesquisa será incrementada em momento posterior. Por ora, queremos apenas acrescentar que, sob o critério do sentido, uma outra subdivisão seria ainda possível: a que reconsiderasse os casos de co-significação e de recategorização lexical. Desse modo, em meio às formas referenciais lexicais, teríamos como co-significativas as repetições e os sinônimos, apenas; como recategorizadoras, teríamos os grupos nominais definidos, os hiperônimos e os nomes genéricos. Sobrariam, numa categoria à parte, as anáforas indiretas e os encapsuladores em geral.

\section{Conclusão: esboço de uma proposta classificatória}

Esta breve revisão dos recursos coesivos, que os distribui segundo a ótica da referenciação, tem o propósito de enfatizar a necessidade de se emparelhar duas perspectivas irmãs que pouco se encontram nos estudos da Linguiística de Texto. Vale congregá-las num curso único que desemboque no exame da construção da coerência e revele os vários dispositivos de que dispõe a língua para remodelar os sentidos. Longe de ser exaustiva, esta classificação representa o passo inicial de uma reflexão que pode vir a ser profícua.

\section{Referências}

APOTHÉLOZ, D., REICHLER-BÉGUELIN, M-J. Interpretations and functions of demonstrative NPs in indirect anaphora. Journal of Pragmatics. 1999, 31. p. 363-97.

BEAUGRANDE, R., DRESSLER, W.U. New foundations for a science or text and discourse: cognition, communication, and freedom of access to knowledge and society. Norwood, New Jersey: Abex, 1981.

BROWN, G.; YULE, G. Discourse analysis. Cambridge: Cambridge University Press, 1983.

CAVALCANTE, M. M. Expressões indiciais em contextos de uso: por uma caracterização dos dêiticos discursivos. Recife, 2000. 205p. Tese (Doutorado em Linguística) - Universidade Federal de Pernambuco (UFPE).

COSTA VAL, M. da G. Redação e textualidade. São Paulo: Martins Fontes, 1991.

EHLICH, K. Anaphora and deixis: same, similar, or different? In: JARVELLA, R.J.; KLEIN, W. (Eds.) Speech, place and action: studies in deixis and related topics. New York: John Wiley and Sons, 1982. p. 315-338.

FONSECA, J. Lingüística e texto/discurso: teoria, descrição, aplicação. Lisboa: Ministério da Educação; Instituto de Cultura e Língua Portuguesa, 1992.

GRICE, P. Logic and conversation. In: COLE, P.; MORGAN, J. L. (Orgs.). Syntax and semantics. New York: Academic Press. v. 2, 1975. 
HALLIDAY, M. A. K.; HASAN, R. Cohesion in spoken and written English. Londres: Longman, 1976.

KOCH, I. G. V. A coesão textual. São Paulo: Contexto, 1989.

Desvendando os segredos do texto. São Paulo: Cortez, 2002.

MARCUSCHI, L. A. Linguiística de texto: o que é e como se faz. Série Debates. Recife: UFPE, 1983.

VILELA, M.; KOCH, I. V. Gramática da língua portuguesa. Coimbra: Almedima, 2001. 